\title{
Malignant Profile Detected by CT Angiographic Information Predicts Poor Prognosis despite Thrombolysis within Three Hours from Symptom Onset
}

\author{
Volker Puetz ${ }^{a, b} \quad$ Imanuel Dzialowski ${ }^{a}$ b Michael D. Hill ${ }^{b}$ \\ Nikolai Steffenhagen ${ }^{\mathrm{b}}$ Shelagh B. Coutts ${ }^{\mathrm{b}}$ Christine O'Reilly ${ }^{\mathrm{b}}$ \\ Andrew M. Demchuk ${ }^{b}$ for the Calgary CTA Study Group \\ ${ }^{a}$ Department of Neurology, Dresden University Stroke Center, University of Technology Dresden,

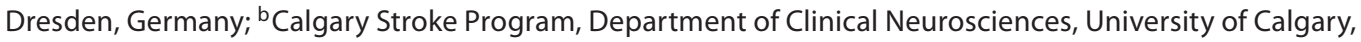 \\ Calgary, Alta., Canada
}

\section{Key Words}

Acute stroke $\cdot \mathrm{CT}$ angiography $\cdot$ Stroke, functional outcome $\cdot$ Thrombolysis

\begin{abstract}
Objective: A malignant profile of early brain ischemia has been demonstrated in the Diffusion and Perfusion Imaging Evaluation for Understanding Stroke Evolution (DEFUSE) trial. Patients with a malignant profile had a low chance for an independent functional outcome despite thrombolysis within 3-6 h. We sought to determine whether CT angiography (CTA) could identify a malignant imaging profile within $3 \mathrm{~h}$ from symptom onset. Methods: We studied consecutive patients (04/02-09/07) with anterior circulation stroke who received CTA before intravenous thrombolysis within $3 \mathrm{~h}$. We assessed the Alberta Stroke Program Early CT Score (ASPECTS) on CTA source images (CTASI). Intracranial thrombus burden on CTA was assessed with a novel 10-point clot burden score (CBS). We analyzed percentages independent (modified Rankin Scale score $\leq 2$ ) and fatal outcome at 3 months and parenchymal hematoma rates across categorized combined CTASI-ASPECTS + CBS score groups where 20 is best and 0 is worst. Results: We identified 114 patients
\end{abstract}

(median age 73 years [interquartile range 61-80], onset-totPA time 129 min [95-152]). Among 24 patients (21\%) with extensive hypoattenuation on CTASI and extensive thrombus burden (combined score $\leq 10)$, only 4\% (1/24) were functionally independent whereas mortality was 50\% (12/24). In contrast, $57 \%$ (51/90) of patients with less affected scores (combined score 11-20) were functionally independent and mortality was $10 \%$ (9/90; $p<0.001)$. Parenchymal hematoma rates were $30 \%(7 / 23)$ vs. $8 \%(7 / 88)$, respectively ( $p=0.008)$. Conclusion: CTA identifies a large hyperacute stroke population with high mortality and low likelihood for independent functional outcome despite early thrombolysis.

Copyright $\odot 2010$ S. Karger AG, Basel

\section{Introduction}

Some stroke patients will have a poor functional outcome despite early intravenous (IV) thrombolysis with alteplase (rtPA) [1]. A magnetic resonance imaging (MRI)-based malignant profile of early brain ischemia has been demonstrated in the Diffusion and Perfusion Imaging Evaluation for Understanding Stroke Evolution (DEFUSE) study and the Echoplanar Imaging Thrombo-

\section{KARGER}

Fax +41613061234 E-Mail karger@karger.ch www.karger.com
(C) 2010 S. Karger AG, Base

$1015-9770 / 10 / 0296-0584 \$ 26.00 / 0$

Accessible online at:

www.karger.com/ced
Volker Puetz, MD

Department of Neurology, Dresden University Stroke Center

University of Technology Dresden, Fetscherstrasse 74, DE-01307 Dresden (Germany)

Tel. +49351 458 3565, Fax +49351458 4365

E-Mail volker.puetz@neuro.med.tu-dresden.de 
lytic Evaluation Trial (EPITHET) $[2,3]$. Patients with a malignant profile, characterized by a large lesion volume on diffusion-weighted imaging (DWI) and/or perfusion imaging (PI), had a low chance (17 and $18 \%$, respectively) for an independent functional outcome if thrombolyzed within 3-6 h from symptom onset.

Compared with MRI, non-contrast CT (NCCT) is more widely available in local general hospitals where most stroke patients present [4]. Quantification of early ischemic changes on the pre-treatment NCCT identifies patients who are unlikely to achieve an independent functional outcome despite thrombolysis within $3 \mathrm{~h}$ from onset [1]. However, the percentage of patients who have extensive early ischemic changes in NCCT is low and their functional outcomes are variable $[1,5-7]$.

CT angiography (CTA) is increasingly performed in the emergency department and can reliably determine intracranial vascular status [8]. More proximal intracranial arterial occlusions are associated with low recanalization rates, likely due to larger thrombus burden [9-11]. Moreover, areas with hypoattenuation on CTA source images (CTASI) may delineate brain tissue with ischemic damage $[12,13]$. CT perfusion techniques have also been evaluated in small series of stroke patients receiving IV rtPA [14].

We sought to determine: (1) the frequency of patients with acute ischemic stroke who have extensive hypoattenuation on CTASI and/or large intracranial thrombus burden on CTA, and (2) whether these patients have a poor functional outcome despite IV thrombolysis within $3 \mathrm{~h}$ from symptom onset.

\section{Methods}

\section{Patients}

We retrospectively studied consecutive (April 2002-September 2007) IV rtPA-treated patients undergoing baseline CTA with a final diagnosis of acute anterior circulation ischemic stroke admitted to Foothills Medical Centre in Calgary. NCCT is the default imaging modality in patients with suspected acute ischemic stroke in our center and followed immediately by CTA prior to IV rtPA treatment. CTA was only sporadically performed at the beginning of the study period evolving to frequent use in IV rtPAtreated patients at the end of the study period. The decision to proceed to CTA is at the discretion of the treating stroke neurologist. For this study we included patients who underwent CTA of the circle of Willis before IV thrombolysis with rtPA within $3 \mathrm{~h}$ from symptom onset. We included subjects who underwent additional neurointerventional treatment after IV rtPA treatment in the form of intraarterial (IA) thrombolysis and/or mechanical device use. Exclusion criteria were pre-morbid modified Rankin Scale ( $\mathrm{mRS}$ ) score $>2$ and final diagnosis of posterior circulation stroke. Clinical baseline variables including the National Institute of Health Stroke Scale (NIHSS) score and mRS score are routinely recorded prospectively in the patient record. In cases where these scores were unavailable, they were derived retrospectively [15].

Functional outcome is recorded prospectively at 3 months in a stroke follow-up clinic. Missing functional outcome data were imputed from the discharge $\mathrm{mRS}$ using the last-score-carried-forward principle. Functional independence was defined as mRS scores $\leq 2$. This study was approved by the local institutional ethics committee.

\section{Imaging}

Standard non-helical NCCT was performed on a multislice CT scanner (GE Medical Systems or Siemens) using $120 \mathrm{kV}, 170$ $\mathrm{mAs}$ with 5-mm slice thickness. Coverage was from skull base to vertex with continuous axial slices parallel to the orbitomeatal line. NCCT was followed by CTA with a helical scan technique. Acquisitions were obtained after a single bolus IV contrast injection of 90-120 ml non-ionic contrast media into an antecubital vein at 3-5 $\mathrm{ml} / \mathrm{s}$. Imaging was auto-triggered by the appearance of contrast material in the ascending aorta. Minimum coverage was from foramen magnum to centrum semiovale with 0.6 - to $1.25-\mathrm{mm}$ slice thickness. Multiplanar volume-reformatted images were immediately created by the CT technologist with 2.5 - to $4.0-\mathrm{mm}$ slice thickness in axial, sagittal and coronal planes. This image reformatting was typically completed within minutes and available for review.

Follow-up NCCT was performed routinely and follow-up MRI as indicated by the treating stroke neurologist. Follow-up imaging had to be performed between day 1 and day 7 after symptom onset to be assessed for final infarct extension.

\section{Image Analysis}

We prospectively and independently applied the Alberta Stroke Program Early CT Score (ASPECTS) to all baseline NCCT, CTASI and follow-up scans by 3 -reader consensus with readers blinded to clinical information and functional outcome. An ASPECT score of 10 indicates a normal scan, a score of 0 indicates ischemic changes in the complete middle cerebral artery (MCA) territory $[5,16]$. On NCCT, early ischemic changes were defined as parenchymal hypoattenuation. On CTASI, regions of relatively diminished contrast enhancement were scored as abnormal [17]. On follow-up NCCT, we applied ASPECTS to regions of subacute brain infarction. On follow-up MRI we similarly scored hyperintense regions on DWI sequences [18]. Hemorrhagic transformation (HT) on follow-up scan was categorized parenchymal hematoma $(\mathrm{PH})$ or hemorrhagic infarction (HI) by ECASS criteria [19].

\section{Assessment of Thrombus Extent}

Intracranial thrombus extent on CTA was assessed with a novel clot burden score (CBS) [20]. CBS allots major intracranial anterior circulation arteries 10 points for contrast opacification on CTA. Two points each are subtracted for occlusive thrombus preventing contrast opacification in the proximal M1, distal M1 or supraclinoid internal carotid artery (ICA) and 1 point each for M2 branches, A1 or infraclinoid ICA. A score of 10 indicates absence of a visible intracranial occlusion on CTA; a score of 0 indicates occlusion of all major intracranial anterior circulation arteries. 

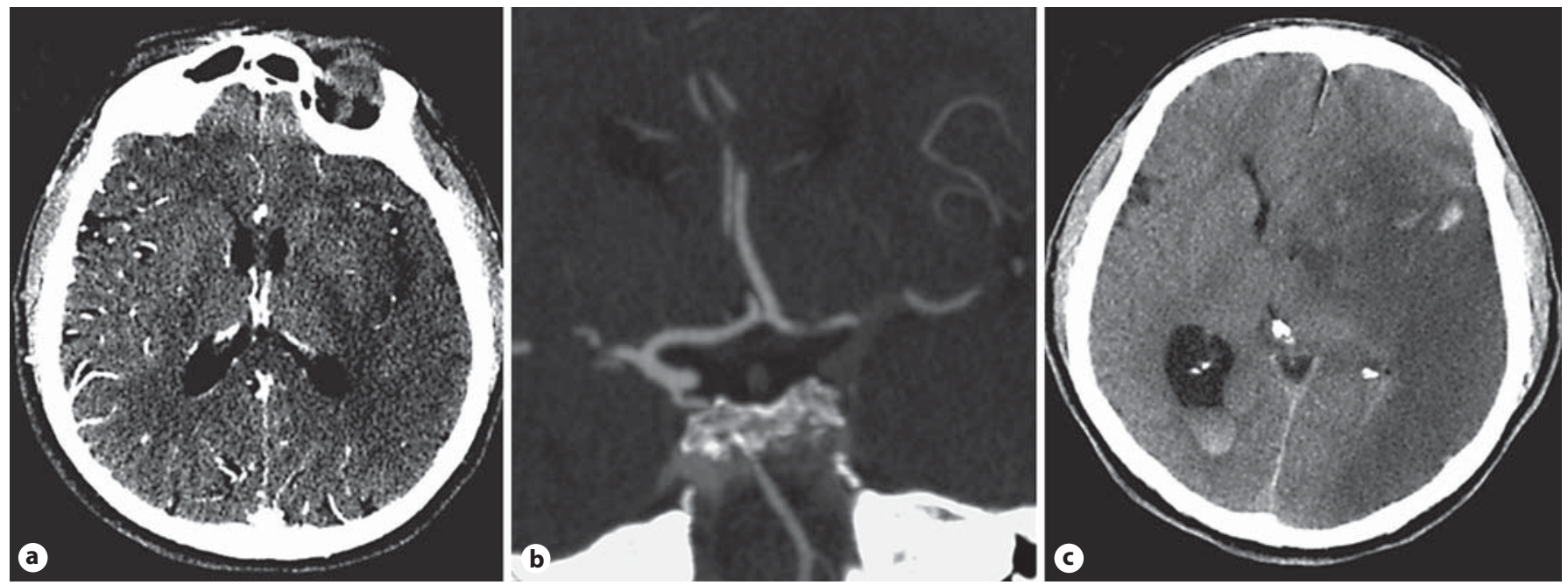

Fig. 1. a CTASI demonstrate extensive hypoattenuation. The ASPECTS on CTASI was rated as 3. b CTA demonstrates occlusion of infraclinoid ICA, supraclinoid ICA and proximal M1-segment. CBS was rated as 5 . The combined CTASI-ASPECTS + CBS score was 8. c Follow-up NCCT showed malignant MCA infarction.

\section{Statistical Analysis}

Data are reported using standard descriptive statistics. We calculated Spearman's rank correlation coefficient to assess the association of the ASPECTS score on CTASI and the CBS score. We combined the two scores (CTASI-ASPECTS and CBS) to an additive score where 20 is best and 0 is worst. A review of the distribution of the mRS scores according to the combined CTASI-ASPECTS + CBS score values suggested that combined score values in two categories $(>10$ and $\leq 10)$ discriminated favorable functional outcome from unfavorable functional outcome and death. We analyzed percentages independent functional outcome (mRS score $\leq 2$ ) and fatal outcome at 3 months and $\mathrm{PH}$ rates across dichotomized combined CTASI-ASPECTS + CBS score groups $(>10$ vs. $\leq 10)$. The distribution of outcomes among these groups was compared with the Fisher's exact test. We performed C-statistics to analyze the discriminative ability of baseline imaging scores to predict favorable functional outcome and calculated univariate Spearman's rank correlation coefficients to assess the association of baseline imaging scores with 3-month mRS scores.

\section{Results}

\section{Clinical Baseline Characteristics}

From a database containing 1,104 consecutive patients who underwent NCCT and CTA for acute cerebrovascular ischemia, 167 patients had a final diagnosis of anterior circulation stroke and received IV thrombolysis with rtPA. Among these, IV thrombolysis was initiated within $3 \mathrm{~h}$ from symptom onset and after CTA in 114 patients. These were 62 men with a median (interquartile range [IQR]) age of 73 years (61-80), baseline NIHSS score of 14 (9-19), on-
set-to-CTA time of $97 \mathrm{~min}$ (73-129) and onset-to-rtPA time of 129 min (95-152). We treated 22 patients (19\%) with additional IA thrombolysis $(n=20)$ or mechanical embolectomy with the Mechanical Embolus Removal in Cerebral Ischemia $\left(\mathrm{MERCI}^{\odot}\right)$ clot retriever $(\mathrm{n}=2)$.

\section{Imaging Baseline Characteristics}

The overall median (IQR) ASPECTS on baseline NCCT was 8 (6-10) and the median (IQR) ASPECTS on baseline CTASI was 7 (5-10). 74 patients (65\%) had a demonstrable intracranial arterial occlusion on CTA. The overall distribution of CBS values was right-skewed with a median CBS of 9 (6-10). The CBS showed a moderate positive correlation (Spearman's $\rho=0.65$; $p<0.001$ ) with the ASPECTS on CTASI, however with a large range of CBS scores at a given CTASI-ASPECTS value.

\section{Patients with Extensive Thrombus Burden and/or \\ Extensive Hypoattenuation on CTASI}

Twenty-four patients (21\%) had extensive hypoattenuation on CTASI and/or extensive thrombus burden with a combined CTASI-ASPECTS + CBS score $\leq 10$ (fig. 1). Baseline characteristics according to the dichotomized combined score are summarized in table 1. Patients with a combined score $\leq 10$ had higher baseline NIHSS scores $(\mathrm{p}<0.001)$ and were more frequently treated with additional IA therapies $(p=0.018)$. Further clinical baseline parameters including the onset-to-CTA time were similar between both groups. All individual baseline imaging 
Table 1. Clinical baseline characteristics according to dichotomized CTASI-ASPECTS + CBS score groups

\begin{tabular}{|c|c|c|c|}
\hline \multirow[t]{2}{*}{ Characteristic } & \multicolumn{2}{|c|}{ CTASI-ASPECTS + CBS score } & \multirow[t]{2}{*}{$\mathrm{p}$ value } \\
\hline & $\leq 10$ & $>10$ & \\
\hline Patients & 24 & 90 & - \\
\hline Age, years, median (IQR) & $72(62-80)$ & $73.5(60-81)$ & 0.66 \\
\hline Male sex, n (\%) & $10(42)$ & $52(58)$ & 0.17 \\
\hline NIHSS score, median (IQR) & $19(18-22)$ & $12(8-17)$ & $<0.001$ \\
\hline \multicolumn{4}{|l|}{ Risk factors, n (\%) } \\
\hline Diabetes & $3(13)$ & $11(12)$ & 1 \\
\hline Arterial hypertension & $9(38)$ & $54(60)$ & 0.06 \\
\hline Hypercholesterolemia & $2(8)$ & $19(21)$ & 0.24 \\
\hline Atrial fibrillation & $5(21)$ & $16(18)$ & 0.77 \\
\hline Coronary artery disease & $6(25)$ & $24(27)$ & 1 \\
\hline Onset-to-CTA, min, median (IQR) & $97.5(78-120)$ & $94.5(72-131)$ & 0.78 \\
\hline Onset-to-tPA, min, median (IQR) & $128.5(90-152)$ & $129(96-152)$ & 0.97 \\
\hline Additional IA therapy, n (\%) & $9(38)$ & $13(14)$ & 0.018 \\
\hline MERCI clot retriever, n (\%) & $1(4)$ & $1(1)$ & 0.38 \\
\hline IA rtPA, n (\%) & $8(33)$ & $12(13)$ & 0.033 \\
\hline \multicolumn{4}{|l|}{ Imaging parameters } \\
\hline NCCT-ASPECTS, median (IQR) & $5(3-7)$ & $9(7-10)$ & $<0.001$ \\
\hline CTASI-ASPECTS, median (IQR) & $2.5(1-4)$ & $9(6-10)$ & $<0.001$ \\
\hline CBS, median (IQR) & $6(4-6)$ & $9(8-10)$ & $<0.001$ \\
\hline
\end{tabular}

CTASI = CT angiography source images; ASPECTS = Alberta Stroke Program Early CT Score; CBS = clot burden score; IA = intraarterial; MERCI = Mechanical Embolus Removal in Cerebral Ischemia.

Table 2. Ability of baseline variables to discriminate independent and poor functional outcome (defined by area under the receiver operator characteristic [ROC] curve) and univariate analysis of baseline variables versus final mRS scores (Spearman's rank correlation coefficient, $r$ )

\begin{tabular}{lllllr}
\hline & $\begin{array}{l}\text { Area under } \\
\text { ROC curve }\end{array}$ & $\begin{array}{l}\mathrm{p} \\
\text { value }\end{array}$ & $\begin{array}{r}\text { Correla- } \\
\text { tion coef- } \\
\text { ficient }(\mathrm{r})\end{array}$ & $\begin{array}{l}\mathrm{p} \\
\text { value }\end{array}$ \\
\hline NCCT-ASPECTS & 0.63 & 0.017 & -0.25 & 0.008 \\
CTASI-ASPECTS & 0.66 & 0.004 & -0.32 & 0.001 \\
CTASI-ASPECTS + CBS & 0.69 & $<0.001$ & -0.36 & $<0.001$ \\
NIHSS score & 0.8 & $<0.001$ & 0.59 & $<0.001$ \\
\hline
\end{tabular}

NCCT $=$ Non-contrast CT; CTASI $=$ CT angiography source images; ASPECTS = Alberta Stroke Program Early CT Score; $\mathrm{CBS}=$ clot burden score; NIHSS $=$ National Institute of Health Stroke Scale.

CTA Predicts Poor Outcome despite Early Thrombolysis

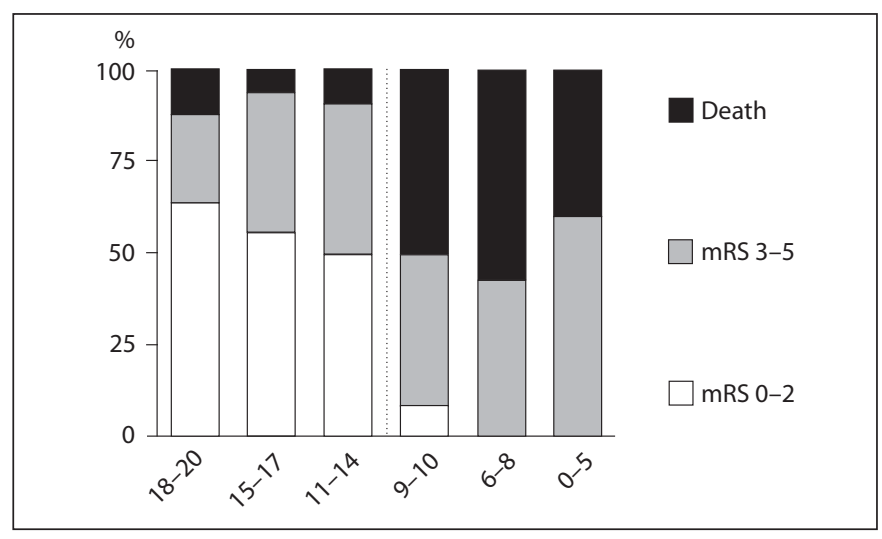

Fig. 2. Clinical outcome at 3 months for categorized CTASI-ASPECTS + CBS score groups where 20 is best and 0 is worst. Patients with a combined score (CS) $\leq 10$ are very unlikely to achieve an independent functional outcome despite thrombolysis within $3 \mathrm{~h}$ from symptom onset (numbers of patients in each group: CS 1820, $\mathrm{n}=42$; CS 15-17, $\mathrm{n}=26$; CS 11-14, $\mathrm{n}=22$; CS 9-10, $\mathrm{n}=12$; CS $6-8, \mathrm{n}=7$; CS $0-5, \mathrm{n}=5$ ). 
Table 3. Clinical and imaging baseline characteristics according to treatment modality

\begin{tabular}{llcl}
\hline \multirow{2}{*}{ Characteristic } & \multicolumn{2}{l}{ Treatment modality } & \multirow{2}{*}{ p value } \\
\cline { 2 - 3 } & IV only & IV-IA & \\
\hline Patients & 92 & 22 & \\
Age, years, median (IQR) & $74(62-82)$ & $69(57-75)$ & 0.018 \\
Male sex, n (\%) & $50(54)$ & $12(55)$ & 1 \\
NIHSS score, median (IQR) & $13(8-18)$ & $17(11-21)$ & 0.036 \\
Onset-to-CTA, min, median (IQR) & $97(75-131)$ & $86.5(66-122)$ & 0.31 \\
Onset-to-tPA, min, median (IQR) & $130(96-152)$ & $122.5(88-150)$ & 0.35 \\
Imaging parameters & & & \\
$\quad$ NCCT-ASPECTS, median (IQR) & $8(6-10)$ & $7(5-8)$ & 0.082 \\
CTASI-ASPECTS, median (IQR) & $8(6-10)$ & $5(3-6)$ & $<0.001$ \\
CBS, median (IQR) & $9(7-10)$ & $6(5-8)$ & $<0.001$ \\
Combined score, median (IQR) & $17(14-20)$ & $11(9-13)$ & $<0.001$ \\
Combined score $\leq 10, \mathrm{n}(\%)$ & $15(16)$ & $9(41)$ & 0.018 \\
\hline
\end{tabular}

NCCT $=$ Non-contrast CT; CTASI $=$ CT angiography source images; ASPECTS = Alberta Stroke Program Early CT Score; CBS = clot burden score; IV = intravenous; IA = intraarterial.

parameters were lower in patients with a combined score $\leq 10$ compared to patients with a combined score $>10$ $(\mathrm{p}<0.001$ for all; table 1$)$.

\section{Functional Outcome}

At 3 months, $46 \%(52 / 114)$ of patients were functionally independent, $36 \%$ (41/114) were functionally dependent and 18\% (21/114) were deceased. Figure 2 shows the distribution of functional outcomes according to categorized combined CTASI-ASPECTS + CBS score groups. Of patients with a combined CTASI-ASPECTS + CBS score $\leq 10$, only $4 \%(1 / 24)$ achieved an independent functional outcome. IV thrombolysis in this patient was started 90 min from symptom onset. In contrast, mortality in this group was $50 \%(12 / 24)$. Of patients with less affected scores (combined CTASI-ASPECTS + CBS score 11-20), $57 \%$ (51/90) were functionally independent and $10 \%$ $(9 / 90)$ were deceased (Fisher's exact test; $\mathrm{p}<0.001)$.

C-statistics demonstrated additional discriminative ability of the combined CTASI-ASPECTS + CBS score compared to the NCCT-ASPECTS and the CTASIASPECTS (table 2). In parallel, univariate analysis demonstrated a better correlation of the combined CTASIASPECTS + CBS score compared to the individual ASPECTS scores with outcome mRS (table 2). The ability of all imaging scores to discriminate independent functional outcome from poor functional outcome was less than the discriminative ability of the baseline NIHSS score (table 2).

\section{Comparison of Patients with IV Thrombolysis and Combined IV-IA Therapy}

Ninety-two patients were treated with IV thrombolysis only and 22 patients received additional IA therapies. Patients who received additional IA therapies were younger, had higher baseline NIHSS scores and more frequently had a combined CTASI-ASPECTS + CBS score $\leq 10$ (table 3). Among 92 patients treated with IV thrombolysis only, 43 (47\%) were functionally independent at 3 months compared to 9 of $22(41 \%)$ patients treated with combined IV-IA therapies (Fisher's exact test, $\mathrm{p}=0.64$ ). Among patients with a combined CTASI-ASPECTS + CBS score $\leq 10$, only 1 of $15(7 \%)$ patients treated with IV thrombolysis and none of $9(0 \%)$ patients who received additional IA therapies achieved an independent functional outcome.

\section{Imaging Outcome}

Follow-up images were available for review in $111 \mathrm{pa}-$ tients. The overall median ASPECTS on follow-up images was 7 (4-8). The median ASPECTS on follow-up images was lower among patients with a combined score $\leq 10$ compared to patients with a combined score $>10(2[0-5]$ vs. 7 [5-9], respectively; p <0.001). Overall, 38 of $111(34 \%)$ patients had hemorrhagic transformation on follow-up images with $\mathrm{PH}$ in 14 patients (13\%) and $\mathrm{HI}$ in 24 patients (22\%). $\mathrm{PH}$ rates were $30 \%$ (7/23) among patients with a combined score $\leq 10$ compared to $8 \%$ (7/88) among patients with a combined score $>10$, respectively (Fisher's exact test; $\mathrm{p}=0.008$ ). 


\section{Discussion}

This study demonstrates that rapidly obtainable CT angiographic information combining the extent of hypoattenuation on CTASI and the intracranial thrombus burden on CTA identifies a large $(21 \%$ of all patients in this study) hyperacute stroke population with a high mortality and very low likelihood for an independent functional outcome despite IV thrombolysis or combined IVIA therapy initiated within $3 \mathrm{~h}$ from symptom onset.

Extensive early ischemic changes on NCCT indicated a low chance of achieving an independent functional outcome in the NINDS rtPA stroke study and the Canadian Alteplase for Stroke Effectiveness Study (CASES) [1, 7]. However, the proportion of patients with extensive early ischemic changes, defined as an ASPECTS of $\leq 4$, was only $10.9 \%$ (66/608 patients) in the NINDS rtPA stroke study and $4.4 \%$ (41 of 936 patients) in CASES, respectively $[1,7]$. Moreover, functional outcomes of patients with extensive early ischemic changes are variable [7].

CTASI are more sensitive for detection of infarction and more accurate for predicting the final infarct size and clinical outcome compared with NCCT [17, 21, 22]. Large lesion volumes on CTASI identified patients with MCA occlusion who had a poor functional outcome despite recanalization of the MCA within $6 \mathrm{~h}$ from symptom onset [12]. In the same time window (i.e. $6 \mathrm{~h}$ from onset), the CTASI lesion volume predicted functional outcome in patients with MCA M1-segment occlusion regardless of the recanalization status in a study by Rosenthal et al. [23]. In our study, the discriminative ability of the combined CTASI-ASPECTS + CBS score to predict independent functional outcome was improved compared to the baseline ASPECTS on NCCT and CTASI. Of note, the discriminative ability of the baseline NIHSS score was higher compared to all baseline imaging scores which is in line with previous data published by our group [7].

Time from symptom onset was the only additional independent predictor of functional outcome among patients in whom recanalization was achieved in the study by Rosenthal et al. [23]. In line with these results, 1 patient in our study achieved an independent functional outcome despite a low combined score. This patient was treated ultra early, i.e. within $90 \mathrm{~min}$ from symptom onset. The information derived from CTASI may vary. In early time windows, CTASI may represent something akin to time-to-peak maps with potentially reversible hypoattenuation with recanalization [12]. In later time windows, CTASI may behave more like a cerebral blood vol- ume parameter map which is highly predictive of the final infarct volume [22].

We have recently shown that the intracranial thrombus extent, assessed with a novel CBS applied on CTA, predicts functional outcome in patients with acute cerebral ischemia [20]. Adopting the same score, Tan et al. [24] have demonstrated lower recanalization rates in patients with low CBSs (i.e. large thrombus burden) compared to patients with high CBSs (i.e. small thrombus burden). As recanalization is unlikely in patients with high thrombus burden, the combined assessment of hypoattenuation on CTASI (CTASI-ASPECTS) and intracranial thrombus burden on CTA (CBS) may identify patients who have a poor functional outcome despite early IV thrombolysis. Such patients may have similar characteristics as patients with an MRI-based malignant profile in the DEFUSE study and the EPITHET trial [2,3]. Comparison of multimodal stroke MRI and CTA in predicting functional outcome may be possible in ongoing trials like the Efficacy and Safety Study of Desmoteplase to treat Acute Ischemic Stroke (DIAS-3) [25]. Moreover, such patients may benefit from early aggressive treatment paradigms like immediate combined IV-IA therapy as currently tested in the Interventional Management of Stroke 3 (IMS-3) trial [26]. A low combined CTASI-ASPECTS + CBS score was associated with poor functional outcome regardless of the treatment modality (IV thrombolysis vs. combined IV-IA therapy) in our study, although the small size of the study hinders definitive conclusions.

Our study is limited by the retrospective study design and monocentric data analysis. Moreover, as not all acute stroke patients in our center received CTA before thrombolytic therapy, results of our study may have been influenced by selection bias. The relatively large number of patients who have evidence of an intracranial arterial occlusion on CTA may point to this limitation (i.e. selection bias). However, the median NIHSS score in our study (14) is similar to the median NIHSS scores of patients in the pooled analysis of randomized controlled thrombolysis trials and patients in the SITS-MOST registry, suggesting that patients in our study represent an average IV rtPAtreated stroke population [27, 28]. Due to the retrospective study design we do not have recanalization data and also did not systematically collect information regarding hyperdense MCA signs which have been shown to predict outcome in large rtPA registries [29]. The poor functional outcome of patients with a low combined score may have partially been due to a self-fulfilling prophecy as physicians may have limited patient care in early treat- 
ment phases due to expectation of a poor functional outcome $[30,31]$. We included patients who received additional IA therapies after initiation of IV thrombolysis. However, the decision to treat with additional IA therapies was not influenced by the combined CTASI-ASPECTS and CBS score. Moreover, the functional outcome in patients with low combined scores was poor in all but 1 patient regardless of the treatment modality in our study.

In summary, patients with a low combined CTASIASPECTS plus CBS score are unlikely to achieve an independent functional outcome despite IV thrombolysis or combined IV-IA therapy initiated within $3 \mathrm{~h}$ from symptom onset. It needs to be determined which of these patients benefit from IV thrombolysis, which may be actually harmed with IV thrombolysis and which may benefit from more aggressive treatment paradigms like immediate combined IV-IA therapy. Ongoing studies like the IMS-3 trial may help to answer this question [26]. We suspect that the answer to this question will vary by stroke onset-to-treatment time.

\section{Acknowledgements}

V.P. was supported by grants from the German Federal Ministry of Education and Research (NBL-3, grant 01 ZZ 0502), M.D.H. was funded by the Alberta Heritage Foundation for Medical Research and the Heart \& Stroke Foundation of Alberta, NWT and Nunavut, and A.M.D. received salary support from Alberta Heritage Foundation for Medical Research. The study was supported from funding from the Heart and Stroke Foundation of Alberta, NWT and Nunavut.

\section{References}

1 Demchuk AM, Hill MD, Barber PA, Silver B, Patel SC, Levine SR: Importance of early ischemic computed tomography changes using ASPECTS in NINDS rtPA stroke study. Stroke 2005;36:2110-2115.

2 Albers GW, Thijs VN, Wechsler L, Kemp S, Schlaug G, Skalabrin E, Bammer R, Kakuda W, Lansberg MG, Shuaib A, Coplin W, Hamilton S, Moseley M, Marks MP: Magnetic resonance imaging profiles predict clinical response to early reperfusion: the diffusion and perfusion imaging evaluation for understanding stroke evolution (DEFUSE) study. Ann Neurol 2006;60:508-517.

3 Davis SM, Donnan GA, Parsons MW, Levi C, Butcher KS, Peeters A, Barber PA, Bladin C, De Silva DA, Byrnes G, Chalk JB, Fink JN, Kimber TE, Schultz D, Hand PJ, Frayne J, Hankey G, Muir K, Gerraty R, Tress BM, Desmond PM: Effects of alteplase beyond $3 \mathrm{~h}$ after stroke in the Echoplanar Imaging Thrombolytic Evaluation Trial (EPITHET): a placebo-controlled randomised trial. Lancet Neurol 2008;7:299-309.

4 Handschu R, Garling A, Heuschmann PU, Kolominsky-Rabas PL, Erbguth F, Neundorfer B: Acute stroke management in the local general hospital. Stroke 2001;32:866-870.

5 Barber PA, Demchuk AM, Zhang J, Buchan AM: Validity and reliability of a quantitative computed tomography score in predicting outcome of hyperacute stroke before thrombolytic therapy. Aspects study group. Alberta Stroke Program Early CT Score. Lancet 2000;355:1670-1674.

6 Hill MD, Buchan AM: Thrombolysis for acute ischemic stroke: results of the Canadian Alteplase for Stroke Effectiveness Study. CMAJ 2005;172:1307-1312.
7 Weir NU, Pexman JH, Hill MD, Buchan AM: How well does ASPECTS predict the outcome of acute stroke treated with IV tPA? Neurology 2006;67:516-518.

8 Lev MH, Farkas J, Rodriguez VR, Schwamm LH, Hunter GJ, Putman CM, Rordorf GA, Buonanno FS, Budzik R, Koroshetz WJ, Gonzalez RG: CT angiography in the rapid triage of patients with hyperacute stroke to intraarterial thrombolysis: accuracy in the detection of large vessel thrombus. J Comput Assist Tomogr 2001;25:520-528.

9 Lee KY, Han SW, Kim SH, Nam HS, Ahn SW, Kim DJ, Seo SH, Kim DI, Heo JH: Early recanalization after intravenous administration of recombinant tissue plasminogen activator as assessed by pre- and post-thrombolytic angiography in acute ischemic stroke patients. Stroke 2007;38:192-193.

10 Rha JH, Saver JL: The impact of recanalization on ischemic stroke outcome: a metaanalysis. Stroke 2007;38:967-973.

11 Saqqur M, Uchino K, Demchuk AM, Molina CA, Garami Z, Calleja S, Akhtar N, Orouk FO, Salam A, Shuaib A, Alexandrov AV: Site of arterial occlusion identified by transcranial Doppler predicts the response to intravenous thrombolysis for stroke. Stroke 2007; 38:948-954.

12 Lev MH, Segal AZ, Farkas J, Hossain ST, Putman C, Hunter GJ, Budzik R, Harris GJ, Buonanno FS, Ezzeddine MA, Chang Y, Koroshetz WJ, Gonzalez RG, Schwamm LH Utility of perfusion-weighted CT imaging in acute middle cerebral artery stroke treated with intra-arterial thrombolysis: prediction of final infarct volume and clinical outcome. Stroke 2001;32:2021-2028.
13 Schramm P, Schellinger PD, Klotz E, Kallenberg K, Fiebach JB, Kulkens S, Heiland S, Knauth M, Sartor K: Comparison of perfusion computed tomography and computed tomography angiography source images with perfusion-weighted imaging and diffusion-weighted imaging in patients with acute stroke of less than 6 hours' duration. Stroke 2004;35:1652-1658.

14 Kim JT, Yoon W, Park MS, Nam TS, Choi SM, Lee SH, Kim BC, Kim MK, Cho KH: Early outcome of combined thrombolysis based on the mismatch on perfusion CT. Cerebrovasc Dis 2009;28:259-265.

15 Goldstein LB, Chilukuri V: Retrospective assessment of initial stroke severity with the Canadian Neurological Scale. Stroke 1997; 28:1181-1184

16 Puetz V, Dzialowski I, Hill MD, Demchuk AM: The Alberta Stroke Program Early CT Score in clinical practice: what have we learned? Int J Stroke 2009;4:354-364.

17 Coutts SB, Lev MH, Eliasziw M, Roccatagliata L, Hill MD, Schwamm LH, Pexman JH, Koroshetz WJ, Hudon ME, Buchan AM, Gonzalez RG, Demchuk AM: ASPECTS on CTA source images versus unenhanced CT: added value in predicting final infarct extent and clinical outcome. Stroke 2004;35:24722476.

18 Barber PA, Hill MD, Eliasziw M, Demchuk AM, Pexman JH, Hudon ME, Tomanek A, Frayne R, Buchan AM: Imaging of the brain in acute ischaemic stroke: comparison of computed tomography and magnetic resonance diffusion-weighted imaging. J Neurol Neurosurg Psychiatry 2005;76:1528-1533. 
19 Hacke W, Kaste M, Fieschi C, von Kummer R, Davalos A, Meier D, Larrue V, Bluhmki E, Davis S, Donnan G, Schneider D, Diez-Tejedor E, Trouillas P: Randomised double-blind placebo-controlled trial of thrombolytic therapy with intravenous alteplase in acute ischaemic stroke (ECASS II). Second European-Australasian Acute Stroke Study investigators. Lancet 1998;352:1245-1251.

20 Puetz V, Dzialowski I, Hill MD, Subramaniam S, Sylaja PN, Krol A, O'Reilly C, Hudon ME, Hu WY, Coutts SB, Barber PA, Watson T, Roy J, Demchuk AM: Intracranial thrombus extent predicts clinical outcome, final infarct size and hemorrhagic transformation in ischemic stroke: the clot burden score. Int J Stroke 2008;3:230-236.

21 Camargo EC, Furie KL, Singhal AB, Roccatagliata L, Cunnane ME, Halpern EF, Harris GJ, Smith WS, Gonzalez RG, Koroshetz WJ, Lev MH: Acute brain infarct: detection and delineation with CT angiographic source images versus non-enhanced CT scans. Radiology 2007;244:541-548.

22 Tan JC, Dillon WP, Liu S, Adler F, Smith WS, Wintermark M: Systematic comparison of perfusion-CT and CT-angiography in acute stroke patients. Ann Neurol 2007;61:533543.
23 Rosenthal ES, Schwamm LH, Roccatagliata L, Coutts SB, Demchuk AM, Schaefer PW, Gonzalez RG, Hill MD, Halpern EF, Lev $\mathrm{MH}$ : Role of recanalization in acute stroke outcome: rationale for a CT angiogrambased 'benefit of recanalization' model. AJNR Am J Neuroradiol 2008;29:1471-1475.

24 Tan IY, Demchuk AM, Hopyan J, Zhang L, Gladstone D, Wong K, Martin M, Symons SP, Fox AJ, Aviv RI: CT angiography clot burden score and collateral score: correlation with clinical and radiologic outcomes in acute middle cerebral artery infarct. AJNR Am J Neuroradiol 2009;30:525-531.

25 Efficacy and safety study of desmoteplase to treat acute ischemic stroke (DIAS-3). http:// clinicaltrials.gov/ assessed on August 13, 2009.

26 Khatri P, Hill MD, Palesch YY, Spilker J, Jauch EC, Carrozzella JA, Demchuk AM, Martin R, Mauldin P, Dillon C, Ryckborst KJ, Janis S, Tomsick TA, Broderick J: Methodology of the Interventional Management of Stroke III Trial. Int J Stroke 2008;3:130137.

27 Hacke W, Donnan G, Fieschi C, Kaste M, von Kummer R, Broderick JP, Brott T, Frankel M, Grotta JC, Haley EC Jr, Kwiatkowski T, Levine SR, Lewandowski C, Lu M, Lyden P, Marler JR, Patel S, Tilley BC, Albers G Bluhmki E, Wilhelm M, Hamilton S: Association of outcome with early stroke treatment: Pooled analysis of ATLANTIS, ECASS, and NINDS rt-PA stroke trials. Lancet 2004;363:768-774.
28 Wahlgren N, Ahmed N, Davalos A, Ford GA, Grond M, Hacke W, Hennerici MG, Kaste M, Kuelkens S, Larrue V, Lees KR, Roine RO, Soinne L, Toni D, Vanhooren G: Thrombolysis with alteplase for acute ischaemic stroke in the Safe Implementation of Thrombolysis in Stroke-Monitoring Study (SITS-MOST): an observational study. Lancet 2007;369: 275-282.

29 Kharitonova T, Ahmed N, Thoren M, Wardlaw JM, von Kummer R, Glahn J, Wahlgren $\mathrm{N}$ : Hyperdense middle cerebral artery sign on admission CT scan - prognostic significance for ischaemic stroke patients treated with intravenous thrombolysis in the safe implementation of thrombolysis in Stroke International Stroke Thrombolysis Register. Cerebrovasc Dis 2009;27:51-59.

30 Rabinstein AA, Wijdicks EF: Determinants of outcome in anticoagulation-associated cerebral hematoma requiring emergency evacuation. Arch Neurol 2007;64:203-206.

31 Zahuranec DB, Brown DL, Lisabeth LD, Gonzales NR, Longwell PJ, Smith MA, Garcia NM, Morgenstern LB: Early care limitations independently predict mortality after intracerebral hemorrhage. Neurology 2007; 68:1651-1657. 